\title{
Waiting for diagnostic colonoscopy: a qualitative exploration of screening participants' experiences in a FIT-based colorectal cancer screening program
}

This article was published in the following Dove Press journal:

Patient Preference and Adherence

Pia Kirkegaard'

Adrian Edwards ${ }^{1,2}$

Mette Bach Larsen'

Berit Andersen ${ }^{1,3}$

'Department of Public Health Programmes, Randers Regional Hospital, Randers, Denmark; ${ }^{2}$ Division of Population Medicine, School of Medicine, Cardiff University, Cardiff, UK; ${ }^{3}$ Department of Clinical Medicine, Aarhus University, Aarhus, Denmark

Correspondence: Pia Kirkegaard Department of Public Health Programmes, Randers Regional Hospital, Skovlyvej 15, 8930 Randers NØ,

Denmark

Tel +457842026

Fax +4578424345

Email piakik@rm.dk
Background: Participants in population-based screening for colorectal cancer (CRC) may experience increased anxiety immediately after a positive screening test, but research in this area is limited. The objective of this study was to explore how screening participants experience a positive test result and cope with the pre-diagnostic waiting period in a CRC screening program.

Materials and methods: Screening participants with a positive fecal immunochemical test (FIT) result were identified in the Danish national CRC program before they attended diagnostic colonoscopy. Sixteen screening participants were selected for an interview in their own homes, using a semi-structured interview guide. Transcribed data were analyzed thematically.

Results: The most prominent themes were symptom appraisal and communication strategies. Most participants attributed the positive FIT result showing blood in the stool to pre-existing non-malignant conditions but a few were very worried about the FIT result and the outcome of the colonoscopy. Communication strategies included discussions with family or friends about the positive FIT result and the upcoming colonoscopy, or containing information until the colonoscopy had provided the definitive diagnostic result. There was no apparent need for communication with health care professionals during the pre-diagnostic waiting period.

Conclusion: The pre-diagnostic waiting period between positive FIT result and colonoscopy in a population-based screening program may cause worry for some participants, potentially to require support, but most people consider it unconcerning. Screening providers should communicate to all screening participants in written form that negative emotional responses may occur after a positive screening result. This is particularly important in screening programs using self-sample kits without the presence of a health care professional to reassure the few participants who may experience significant anxiety.

Keywords: health services research, population-based cancer screening, colorectal cancer, fecal testing, coping, qualitative research

\section{Introduction}

Colorectal cancer (CRC) is the second most frequent cause of cancer-related deaths in men and the third most common cancer in women in developed countries. ${ }^{1}$ Screening for CRC can reduce CRC morbidity and mortality, ${ }^{2}$ and therefore population-based screening programs for CRC have been implemented in most European countries. ${ }^{3}$ In countries using fecal tests, ie, fecal immunochemical test (FIT) or guaiac-based test, the screening programs offer self-sample kits. Thus, the first step in the screening procedure may take place without contact with a health care professional. ${ }^{4}$ After a positive screening result, the patient will be referred for a diagnostic colonoscopy. This referral may also be without direct contact with a health care professional, leaving it 
up to the screening participants themselves to cope with possible uncertainty or anxiety and to decide whether to attend it or not.

Clinically relevant short- or long-term adverse psychological impacts have not been consistently shown among screening participants using FIT, but some evidence suggests that screening participants may experience increased anxiety immediately after notification of positive FIT results. ${ }^{5-8}$ However, studies have generally overlooked a potentially important aspect of the CRC screening experience, namely the pre-diagnostic waiting period, and thus descriptions of the ways in which people experience pre-diagnostic waiting and outcome uncertainty during the pre-diagnostic waiting period in CRC screening are limited. ${ }^{9}$

Our aim was to explore how screening participants experience a positive FIT result and cope with the pre-diagnostic waiting period between positive FIT result and colonoscopy in a population-based screening program for CRC. Exploring this period may aid understanding about the significance of the lack of contact with a health care professional to convey individual information about the screening, and help in understanding and addressing the social and psychological mechanisms at work when presumed healthy individuals are confronted with an emergent health threat such as the possibility of a cancer diagnosis.

\section{Materials and methods Setting}

Population-based screening for CRC using FIT was rolled out in Denmark in 2014 for citizens between 50 and 74 years of age. The citizens receive a mailed invitation for the screening program, including standardized information material about screening and CRC, and materials for home-based collection of a fecal sample (self-sampling kit, a feces collection paper, and instructions on how to obtain and mail the sample) to be submitted in a pre-paid, pre-addressed envelope directly to the laboratory.

All screening results were mailed directly to the citizens. Positive screening results were accompanied by a pre-booked appointment for colonoscopy at a local hospital, a diet plan, and a laxative for bowel preparation before the colonoscopy. According to Danish law, the appointment for colonoscopy should be no later than 14 calendar days after the positive screening result. ${ }^{10}$

The study was undertaken in the Central Denmark Region (CDR), which is the second largest region with $1,282,000$ citizens ( $22 \%$ of the Danish population) of whom $\sim 384,000$ were in the target population of the CRC screening program. Since the CRC screening program was launched in 2014, 66\% had returned an FIT sample and 6.6\% had a positive screening result and received a pre-booked appointment to colonoscopy of which $92 \%$ attended the examination. $^{11}$

\section{Design, study participants, and recruitment}

The study focused on experiences, understood as the ways in which people interpret and apply meaning to their lives. ${ }^{12,13}$ To provide an account on how a selected group of people in a specific context experience a particular phenomenon (everyday routine or dramatic moment), the study was designed as an exploratory study based on an interpretive ethnographic tradition in which analysis was undertaken in an inductive manner, searching for patterns of meaning. ${ }^{14}$ The study participants were screening participants who had tested positive in the CRC screening program using FIT, and therefore received an appointment for colonoscopy at a local hospital. A maximum variation sampling strategy was used to encompass both sexes, age more than and less than 65 years, participants with partners or single, and geography (urban/ rural). ${ }^{15}$ We aimed to interview some couples of whom both had participated in screening and at least one had received a positive FIT result. All participants included in this study subsequently attended their colonoscopy appointments.

Study participants were recruited through the call center of the regional screening provider in CDR when they called to change the pre-booked appointment. ${ }^{16} \mathrm{PK}$ instructed a secretary to identify study candidates with a certain age and sex when they called in, and to briefly introduce each candidate to the study. If the candidate wished to participate in the study, she/he was contacted by PK to receive further oral information about the study and to arrange an interview appointment 1-2 days before the colonoscopy appointment. Further, PK provided each participant with contact information in case of questions regarding the study at any point during the study period.

\section{Data collection and analysis}

The interviews were undertaken by PK and took place in the study participants' own homes, and spouses of study participants were asked to participate in joint interviews if available. The interviews followed a dynamic semi-structured interview guide. ${ }^{17}$ It included the following topics: reasons for participating in the screening program and knowledge about CRC, attitudes to screening, symptoms and perceived risk of $\mathrm{CRC}$, social activities and emotional flow during the pre-diagnostic waiting period, and expectations regarding the impending colonoscopy and its outcome. Study participants received written information about the study and signed a 
written consent declaration after conclusion of the interview. They also gave consent for publication. The semi-structured interviews were recorded and listened through carefully by PK before transcription, which was performed by PK and a secretary. The transcribed recordings comprised the datasets that were read and reread to generate codes and search for patterns for thematic analysis, using a funnel-structured research approach based on an interpretive ethnographic tradition. ${ }^{14}$ The initial coding was undertaken by PK and $\mathrm{BA}$ and presented to $\mathrm{MBL}$ and $\mathrm{AE}$ for further discussion, and patterns and themes were discussed in regular meetings to generate new insights. In addition to the semi-structured interviews in the participants' homes, telephone interviews with other participants were performed to challenge the analytical insights from the semi-structured interviews and appraise data saturation or "information power". ${ }^{18}$ The telephone interviews were structured by an interview guide presenting themes generated in the analysis and conducted after the completion of the semi-structured interviews. The iterative process of interpretation, data collection, and ongoing questions continued until consensus was reached among the authors, and interpretations and perspectives were condensed into a coherent analysis.

All quotations in the text are identified by pseudonyms. Individual characteristics are shown in Table 1.

\section{Ethics}

The study complied with the Statements on Ethics of the American Anthropological Association. ${ }^{19}$ It was approved by the Danish Data Protection Agency (j. no 2012-58-0006/116-02-187-15) and did not require further ethical approval in accordance with Danish legislation, ie the Act on Research Ethics Review of Health Research Projects. ${ }^{20}$

\section{Results}

In total, 30 people were invited via the call center. Three declined the invitation to participate. In 5 cases, it was not feasible to make an interview appointment because they had colonoscopy appointments on the same dates. Information power of the sampled cases was continuously appraised

Table I Characteristics of interviewed participants

\begin{tabular}{|c|c|c|c|c|c|c|c|c|}
\hline $\begin{array}{l}\text { Name } \\
\text { (pseudonym) }\end{array}$ & $\begin{array}{l}\text { Sex } \\
\text { (F=female, } \\
\text { M=male) }\end{array}$ & $\begin{array}{l}\text { Age } \\
\text { (years) }\end{array}$ & $\begin{array}{l}\text { Marital } \\
\text { status } \\
\text { (m=married, } \\
\text { s=single) }\end{array}$ & $\begin{array}{l}\text { Talked to } \\
\text { friends }\end{array}$ & $\begin{array}{l}\text { Talked } \\
\text { to family } \\
\text { (other } \\
\text { than } \\
\text { spouse) }\end{array}$ & $\begin{array}{l}\text { Talked to health care } \\
\text { professionals }\end{array}$ & $\begin{array}{l}\text { Previous } \\
\text { colonoscopy }\end{array}$ & $\begin{array}{l}\text { Previously } \\
\text { experienced } \\
\text { visible blood } \\
\text { in the stool/ } \\
\text { hemorrhoids }\end{array}$ \\
\hline \multicolumn{9}{|c|}{ Interviews with spouse present } \\
\hline Judith & $\mathrm{F}$ & 68 & $\mathrm{~m}$ & No & No & No & Yes & Yes/Yes \\
\hline John (spouse) & $M$ & 70 & $\mathrm{~m}$ & & & & & \\
\hline Robert & M & 60 & $\mathrm{~m}$ & No & No & No but wanted to & No & No/No \\
\hline Linda (spouse) & $\mathrm{F}$ & 51 & $\mathrm{~m}$ & & & & & \\
\hline Jane & $\mathrm{F}^{*}$ & 61 & $\mathrm{~m}$ & Yes & Yes & No & No & Yes/Yes \\
\hline Mark & $M^{*}$ & 61 & $\mathrm{~m}$ & Yes & Yes & No & Yes & Yes/Yes \\
\hline Mary & $\mathrm{F}^{*}$ & 74 & $\mathrm{~m}$ & No & Yes & No & Yes & Yes/Yes \\
\hline Peter & $M^{*}$ & 74 & $\mathrm{~m}$ & No & Yes & No & Yes & Yes/Yes \\
\hline \multicolumn{9}{|c|}{ Interviews, individual } \\
\hline Richard & $M$ & 74 & s & Yes & No & No & No & No/Yes \\
\hline Michael & $M$ & 58 & $\mathrm{~m}$ & No & No & No & Yes & Yes/Yes \\
\hline Karen & $\mathrm{F}$ & 60 & $\mathrm{~m}$ & Yes & No & Yes (was going to GP anyway) & Yes & Yes/Yes \\
\hline Frank & $M$ & 67 & $\mathrm{~m}$ & Yes & Yes & Yes (son-in-law is nurse) & Yes & Yes/Yes \\
\hline Christine & $\mathrm{F}$ & 70 & $\mathrm{~m}$ & No & Yes & No & No & No/Yes \\
\hline Connie & $\mathrm{F}$ & 74 & $s$ & Yes & No & Yes (neighbor is nurse) & No & Yes/Yes \\
\hline Thomas & $M$ & 58 & s & Yes & No & Yes (going to GP anyway) & No & Yes/Yes \\
\hline William & $M$ & 69 & s & Yes & No & No & Yes & No/Yes \\
\hline Joan & $\mathrm{F}$ & 71 & $\mathrm{~m}$ & No & No & No & Yes & Yes/Yes \\
\hline Julie & $\mathrm{F}$ & 58 & $\mathrm{~s}$ & Yes & No & No & No & No/No \\
\hline \multicolumn{9}{|c|}{ Telephone interviews } \\
\hline Susan & $\mathrm{F}$ & 74 & $s$ & Yes & Yes & No & No & Yes/No \\
\hline Betty & $\mathrm{F}$ & 74 & s & Yes & Yes & Yes (called GP) & Yes & Yes/No \\
\hline Daniel & $M$ & 74 & $\mathrm{~m}$ & Yes & No & No & Yes & Yes/Yes \\
\hline David & $M$ & 60 & $\mathrm{~m}$ & No & No & No & Yes & Yes/No \\
\hline Kenneth & $M$ & 58 & s & Yes & No & No & No & No/No \\
\hline Brian & $M$ & 59 & $\mathrm{~m}$ & No & No & No & No & No/No \\
\hline
\end{tabular}

Note: *Married couple, both had blood in the stool and had received and accepted an appointment to colonoscopy. 
during the research process, following the funnel-structured analytical approach, in order to adjust sample size for a robust analysis. ${ }^{18}$ After 16 interviews (6 interviews with a spouse present and 10 individual interviews), the validity of the findings was assessed using telephone interviews with the remaining 6 participants. In total, 22 men and women were interviewed (Table 1). Each semi-structured interview in the home lasted for 45-90 minutes, and each structured telephone interview lasted for 10-20 minutes.

Two prominent themes were apparent across the interviews and will be presented in this paper: 1) symptom appraisal of blood in the stool and perceived risk of CRC and 2) communication about the positive FIT result with health care professionals, family and friends.

\section{Symptom appraisal}

Many study participants knew the meaning of getting a "big letter" (which includes an appointment to colonoscopy, a diet plan, and a laxative for bowel preparation before the colonoscopy) the moment they saw it and before they opened it. In some participants, the standardized letter, coming automatically from CDR (ie, not coming from their individual general practitioner), evoked responses characterized by initial alert followed by reasoning that a positive FIT result was most likely an outcome of too sensitive laboratory tests detecting blood stemming from hemorrhoids or small lesions in the bowel, not from cancer. Feeling healthy (though enduring hemorrhoids) often curbed the uncertainty, as illustrated by Mary:

Mary: My husband came in with the letter and said "there's a package for you". Oh no. I could see that the letter came from Central Denmark Region and I thought "That's it". And I was right. Dreadful thoughts took over my mind in that moment. But immediately after, I felt assured and I said to myself that "I feel healthy, I'm not tired, my appetite is good, and I don't have any pain".

She reasoned that the blood in the stool had come from hemorrhoids or polyps, which had caused symptoms before:

Mary: I think it might be hemorrhoids because I have suffered from hemorrhoids in the past, and when I gave birth to my daughter, the hemorrhoids gave me a lot of pain. But I haven't really been troubled by it. I haven't been troubled by it for about ten years. So it is. And then you think "could it be something bad" or "it's probably nothing" or "it's probably hemorrhoids or polyps", and then you pass it off until proven otherwise.
As shown in Table 1, 6 of the study participants had undergone a colonoscopy in the past due to possible suspected cancer. The common experience was that a colonoscopy did not, however, result in a serious bowel disease or cancer diagnosis. Participants did not suspect this time to be any different. Two study participants said they felt anxious when they received the positive FIT result (Robert and Judith). Robert expressed it the following way:

Robert: This is not what I had anticipated at all. I had forgotten all about it between Monday when I took the test and Thursday when I got the result. It was off my mind. We were expecting guests and it was quite frustrating that the letter came in the letterbox just 15 minutes before. I fell silent. No, I had not anticipated that something was wrong.

I had had no symptoms or anything like that.

Robert perceived himself as wholesome and healthy, and he and his wife had participated in the screening program "without giving it much thought". When she got a negative FIT result, he also expected to get one. He was overwhelmed by anxiety to a level that required a silent retreat to their summer house until a day before the colonoscopy (ie, the day of the interview) to ease his mental discomfort.

Robert: I have been absent-minded. I haven't said anything. I have been sad, I really have, especially during the first four or five days. It's on my mind constantly. We went to our summer house and that was good. I could keep away my thoughts about it, except on Saturday. I was really miserable and I wailed. I really did.

Interviewer (to Linda, spouse): could you tell something was wrong?

Linda: Yes indeed. We talked about it once in a while. We were alone ... we were supposed to visit some friends and have guests that week but agreed to retreat to our summer house so he could ruminate about it up there instead. Wander about for a while.

Robert: But after the first four or five days ... I thought I almost preferred to get the instant answer that I have a mild form of cancer, rather than waiting another week. Almost. These 12 days have been tough.

The other person (Judith) suffered from several bowel symptoms and she had a long history of diagnostic procedures including colonoscopy although she had never been diagnosed with cancer. Her husband reported that she had been a worrier for as long as he had known her. When she received the positive FIT result, the feeling of uncertainty was overwhelming and she was worried about both the discomfort of the upcoming colonoscopy and the outcome. 
Judith: I feel miserable, particularly at night. You know, then you start wondering ... I wish I had the ability to take it easy and not trouble trouble before trouble troubles you. But I worry a lot because I have had such a hard time. If only I can get some sedation before the procedure, just like last time where I could sleep during the examination. And then, when it's over, I will cross my fingers and my toes and everything else that can be crossed and hope they'll find nothing.

Her husband remarked that he "tiptoed around her" because she worried so much and some everyday life routines including social entertainment were put on hold.

All the study participants subsequently underwent a colonoscopy although most anticipated that the positive FIT result was a "false alarm" for CRC, triggered by blood in the stool derived from hemorrhoids or polyps. It was felt "better to be on the safe side", as explained by Thomas:

Thomas: I'm sure it's just the stupid hemorrhoids. And I think it's okay just to get it checked, because then it's done, and if it's not okay, I better do something about it.

None of the study participants described themselves as being at a particularly high risk of developing CRC (including Judith and Robert) compared to other people in their age group, but the screening offer made them reconsider the risk of CRC, as explained by Michael:

Michael: I've had trouble with digestion and urinating but that is common for someone my age, right. I've had an examination down there a few years ago to see where the blood came from and they removed some very small polyps and they sent them to a laboratory. It's quite normal to have them. Like hemorrhoids. It doesn't have to be a sign. I don't think I'm any different, but you see cancer everywhere and you start wondering "when is it my turn?"

In sum, interpretations of a positive FIT result and perceived risk of CRC were shaped by symptom appraisal and experiences with previous abdominal symptoms and investigation. A few study participants expressed anxiety, but most of them felt calm and reasoned that the positive FIT result may be a sign of blood in the stool due to benign conditions, not due to cancer.

\section{Communication about the FIT result}

Although many participants said they had anticipated a positive FIT result, the letter from the screening provider still came as an unpleasant surprise. Karen described that she already had an appointment with her general practitioner about discomfort related to menopause and she had thought it might be a good opportunity to talk with a health professional about colonoscopy.

Karen: I look into the mailbox and I see that envelope and

I think to myself: "Oh no". I read the letter briefly. Then

I go to my general practitioner and when I'm there I can talk

to him about the examination. What to do and how.

During the consultation she had only mentioned the appointment briefly and she had not felt the need to discuss it in detail. Instead she and the general practitioner had focused on the menopause symptoms, as originally intended. Four of the study participants reported that they had spoken to a health care professional about the positive FIT result. In 2 cases, health care professionals were part of the participant's close personal network, and another 2 were consulted opportunistically (as in the case of Karen).

Talking about the positive FIT result to family or friends who worked in the health care system was sometimes used as a strategy to get "inside information" about the colonoscopy. For instance, Frank reported that he had had some bad experiences with doctors previously performing a colonoscopy on him due to bleeding and suspicion of cancer, and he emphasized that some doctors were more skillful and sensitive than others.

Frank: Our son-in-law is a nurse, so we tell him about it, of course. He knows a thing or two about the individual doctors' performances. Some of them don't have the best reputation.

Frank had wanted to get a particular doctor to perform the colonoscopy but his son-in-law had assured him that the doctors currently working at the diagnostic department were good at their jobs.

Due to the potential use of a mild sedative before the colonoscopy and due to the risk of bleeding after colonoscopy, the letter containing the appointment informed patients that they should make arrangements for transportation after the examination. This often involved a family member or friend accompanying the patient to and from the hospital, and thus obliged study participants to share information about the appointment with others. Some of the married study participants had not discussed the positive FIT result with family members other than their spouse who had agreed to accompany them to the colonoscopy. As explained by Michael:

Michael: In my mind it is a natural thing to get screened.

You know, my wife goes to breast cancer screening and I believe she has also been screened for cervical cancer.

I have two children in their late twenties and there is no 
reason to upset them, so they don't know that I am going to get an examination on Monday. I think I'll tell them if something's wrong, right. And if nothing's wrong, then it's ok. My daughter in particular, she would be very upset and worried so there is no reason I should tell her now, but if anything was wrong eventually, I would talk to her. Of course I would not keep her in the dark if I need surgery. My children would be informed about that. But in this case, it might be a false alarm, and there is no reason for them to worry about it, when I'm not even worried about it.

Single study participants had involved friends, as exemplified by Thomas:

Thomas: I've involved a friend, I mean, I had to involve her because I need someone to drive me home. You're not allowed to drive home by yourself, so there is no other way around it. I mean, it's just a medical examination.

In this case, the study participant had a previous history of blood in the stool and hemorrhoids, and he reported that he just had a sensitive stomach. He was not pleased with the need to share the information with anybody, mostly because he felt that it then became a dramatic event when it was to him just an ordinary matter to attend an examination.

To other study participants, talking about health with family (adult children) or friends was described as a "natural habit", also when it comes to potentially serious disease. Jane talked about health matters in general and CRC screening in particular when she said:

Jane: Oh yes, we always share these things with our children, and this time we have also talked about it with many of our friends. (...) Many of them have also participated in the program and reached the same level as me. They joked that now my husband is the only one at the dinner table who hasn't received an appointment for colonoscopy.

However, in most cases the study participants wished to contain or delay information to family and friends about the positive FIT result and only disclose information if the positive FIT really was a consequence of cancer, instead of involving others in the pre-diagnostic phase.

In summary, some study participants said they had discussed the positive FIT with friends or family, because health matters are a common and ordinary topic of discussion. Other participants refrained from talking to others about it under the assumption that the information about a positive FIT result was irrelevant to others as long as there was no definitive result (ie, outcome of the colonoscopy). The lack of contact with a health care professional was not a common concern among the study participants.

\section{Discussion}

The positive FIT result showing blood in the stool was often attributed to previous or current hemorrhoids or polyps. The pre-diagnostic waiting period between a positive FIT screening result and a colonoscopy was managed by seeking social support from family or friends, or by containing information, either because it was perceived as an ordinary matter not worth discussing or because it might cause unnecessary worry. Contact with health care professionals was not needed and only used to a limited degree. Most participants carried on with their daily activities, whereas a few participants described significant anxiety while waiting for the colonoscopy.

\section{Strength and limitations}

The Danish CRC program provides a relatively short waiting period of a maximum of 14 calendar days between a positive CRC screening result and the diagnostic colonoscopy. ${ }^{10}$ This specific organizational context should be taken into consideration in attempts to transfer the results to other contexts where waiting periods may be longer.

We recruited participants who contacted the call center in the regional screening provider in CDR to change a prebooked appointment to a colonoscopy. This means that screening-positive citizens who did not wish to attend for colonoscopy were excluded from the recruitment process, and their anxiety or concern levels could be different to attenders (greater or lesser). According to data from the CRC program, $8 \%$ of screening-positive patients do not attend their appointment, and our recruitment design did not allow an exploration of this particular and important group. ${ }^{11}$ Thus, the results in our study may apply only to screening participants who have decided to accept the appointment for colonoscopy.

Data on education level were not obtained from the participants. People with lower educational attainment may have different needs regarding information about CRC screening, and most may prefer only to get information about colonoscopy if their FIT result turns out to be positive. ${ }^{21}$ This may hamper the understanding of consequences of a positive FIT leading to non-adherence to diagnostic colonoscopy across all patient groups. Conclusions from our study might not be applicable to this particular group of people.

We consider it a strength that the interviews were conducted in the privacy of the study participants' own homes 
due to the sensitive topic and to promote trust and confidence with the interviewer, and the findings were supported by data from structured telephone interviews, which were used to appraise the analytical insights and substantiate the categories generated in the semi-structured interviews.

\section{Interpretation and comparison with existing literature}

Blood in the stool is a normal complication of hemorrhoids, which occurs frequently in the adult population. A study about hemorrhoids detected by flexible colonoscopy in a screening program for CRC has shown a total prevalence of $39 \%$ and a prevalence of symptomatic hemorrhoids of $20 \%{ }^{22}$ Studies about health expectations about test results have shown that patients receiving an unexpected test result perceive the test result as less accurate. ${ }^{23,24}$ Our data showed that participants perceived the positive FIT result as accurate in its ability to detect blood, but inaccurate in detecting cancer. Most participants said they were not surprised about the positive FIT, but since they could not dismiss the possibility of CRC, they all wished to get the colonoscopy.

Our study illustrated some screening participants' active engagement in coping with outcome uncertainty. Coping theory discriminates between problem-focused responses, which are dominant when individuals feel they can reduce or eliminate threat, and emotion-focused responses, which are dominant when individuals feel they need to endure a stressful situation. ${ }^{25-27}$ Problem-focused strategies were employed when participants decided to talk to health care professionals for medical advice or "inside information", or with family or friends for practical help. Emotion-focused strategies included communication with family or friends for sharing concern and seeking emotional support. However, in our study, many of those who chose to speak with family or friends reasoned that they did so because it was an ordinary unconcerning matter. They viewed screening participation and the positive FIT result as an event worth discussing, not too dramatic, not too embarrassing or too private for sharing. This finding contrasts the results of other studies that showed that CRC screening and test results are regarded as private..$^{28,29}$ In our study, however, emotion-focused strategies also included strategies of noncommunication by avoiding social contact or by keeping the test result and the outcome uncertainty to themselves, thus supporting the notion of privacy. These participants practiced "bracketing" of uncertainty, putting outcome uncertainty on hold. ${ }^{30}$ Withholding information from others in order to protect them from worry could be a calculus of responsibility, which is practiced until outcome uncertainty is replaced by an outcome. ${ }^{31}$

However, using the concept of coping has its limitations in our study. Coping presupposes a stressful event, and even though a positive FIT result was in some cases perceived as a disruption to participants' everyday lives, it was also a calculated but non-dramatic risk to many of them. Uncertainty is a prominent feature in modern life, ${ }^{32}$ and managing uncertainty is an on-going sense-making process in everyday life. ${ }^{33,34}$ Our study has shown that receipt of a positive screening result might not be a prominent stressful event and people employ different strategies to make symptoms meaningful, such as "normalization" 35 and "personalizing the odds". 25 Normalization implies that information about potential health threats (outcome uncertainty) are rearranged to fit with current experiences (social and personal) with benign and manageable conditions. For example, rectal bleeding or a positive screening test are understood not as alarms for cancer, but as normal expected conditions due to unhealthy diet or age-related diseases such as hemorrhoids. ${ }^{29,35}$ In our study, the blood in the stool was normalized, based on the participants' previous experience with hemorrhoids or polyps and knowledge about the frequency of hemorrhoids in older people.

\section{Conclusion}

A positive screening result may be attributed to pre-existing non-malignant conditions, and different communication strategies may be adopted during the waiting period to manage people's outcome uncertainty. The pre-diagnostic waiting period may cause worry for some participants, potentially to require support, but most people consider it unconcerning. It is important for screening providers to communicate to all screening participants in written form that negative emotional responses may occur after a positive screening result, and contact information to the screening provider should be highlighted. This is particularly important in screening programs using self-sample kits without the presence of a health care professional to reassure the few participants who may experience significant anxiety.

\section{Author contributions}

PK and BA designed the study. PK conducted the data collection, and the initial coding was undertaken by PK and BA. $\mathrm{MBL}$ and $\mathrm{AE}$ were involved in the finalizing work of the analyses, and PK made the final write-up of the manuscript. All the authors read and approved the final manuscript. 


\section{Disclosure}

The authors report no conflicts of interest in this work.

\section{References}

1. Torre LA, Bray F, Siegel RL, Ferlay J, Lortet-Tieulent J, Jemal A. Global cancer statistics, 2012. CA Cancer J Clin. 2015;65(2):87-108.

2. Holme Ø, Bretthauer M, Fretheim A, Odgaard-Jensen J, Hoff G. Flexible sigmoidoscopy versus faecal occult blood testing for colorectal cancer screening in asymptomatic individuals. Cochrane Database Syst Rev. 2013;9:CD009259.

3. Altobelli E, D'Aloisio F, Angeletti PM. Colorectal cancer screening in countries of European Council outside of the EU-28. World $J$ Gastroenterol. 2016;22(20):4946-4957.

4. Faivre J, Dancourt V, Lejeune C. Screening for colorectal cancer with immunochemical faecal occult blood tests. Dig Liver Dis. 2012; 44(12):967-973

5. Orbell S, O'Sullivan I, Parker R, Steele B, Campbell C, Weller D. Illness representations and coping following an abnormal colorectal cancer screening result. Soc Sci Med. 2008;67(9):1465-1474.

6. Kirkøen B, Berstad P, Botteri E, et al. Psychological effects of colorectal cancer screening: participants vs individuals not invited. World $J$ Gastroenterol. 2016;22(43):9631-9641.

7. Bobridge A, Bampton P, Cole S, Lewis H, Young G. The psychological impact of participating in colorectal cancer screening by faecal immunochemical testing - the Australian experience. Br J Cancer. 2014; 111(5):970-975.

8. Kirkøen B, Berstad P, Botteri E, et al. Do no harm: no psychological harm from colorectal cancer screening. Br J Cancer. 2016;114(5):497-504.

9. Vermeer NC, Snijders HS, Holman FA, et al. Colorectal cancer screening: systematic review of screen-related morbidity and mortality. Cancer Treat Rev. 2017;54:87-98.

10. Sundheds- og Ældreministeriet. Bekendtgørelse om maksimale ventetider ved behandling af kræft og visse tilstande ved iskæmiske hjertesygdomme [Act on Maximum Wait to Treatment of Cancer and Certain Conditions Related to Ischemic Heart Disease]. 2015. Danish. Available from: https://www.retsinformation.dk/Forms/R0710.aspx?id=169865. Accessed May 1, 2018.

11. Dansk Tarmkræftscreeningsdatabase. Årsrapport 2015, 6. version. Første 22 måneder af 1 . nationale screeningsrunde [Annual report 2015, 6th version. The first 22 months of the first national screening round]. 2016. Danish. Available from: http://docplayer.dk/66785123-Dansktarmkraeftscreeningsdatabase-aarsrapport-2015-6-version-foerste-22maaneder-af-1-nationale-screeningsrunde.html. Accessed May 1, 2018.

12. Throop CJ. Articulating Experience. Anthropol Theor. 2003;3(2):219-241.

13. Geertz C. The Interpretation of Cultures: Selected Essays. London: Fontana Press; 1993.

14. Hammersley M, Atkinson P. Ethnography: Principles in Practice. 3rd ed. London: Routledge; 2007.

15. Bernard HR. Research Methods in Anthropology: Qualitative and Quantitative Methods. 4th ed. Lanham: AltaMira Press; 2006.

16. Kirkegaard P, Larsen MB, Andersen B. Helpline calling patterns in a colorectal cancer screening program: a cross-sectional study. J Healthc Commun. 2017;2:2.
17. Kvale S. Doing Interviews. Los Angeles: Sage Publications; 2009.

18. Malterud K, Siersma VD, Guassora AD. Sample size in qualitative interview studies. Qual Health Res. 2016;26(13):1753-1760.

19. American Anthropological Association. Statement on Ethics. Available from: http://www.americananthro.org/ParticipateAndAdvocate/ Content.aspx?ItemNumber=1656. Accessed January 9, 2017.

20. The National Committee on Health Research Ethics. Act on Research Ethics Review of Health Research Projects. Available from: http:// www.nvk.dk/english/act-on-research. Accessed June 9, 2017.

21. Kirkegaard P, Mortensen GL, Mortensen SL, Larsen MB, Gabel P, Andersen B. Making decisions about colorectal cancer screening. A qualitative study among citizens with lower educational attainment. Eur J Public Health. 2016;26(1):176-181.

22. Riss S, Weiser FA, Schwameis K, et al. The prevalence of hemorrhoids in adults. Int J Colorectal Dis. 2012;27(2):215-220.

23. Dunn CE, Edwards A, Carter B, Field JK, Brain K, Lifford KJ. The role of screening expectations in modifying short-term psychological responses to low-dose computed tomography lung cancer screening among highrisk individuals. Patient Educ Couns. 2017;100(8):1572-1579.

24. Renner B. Biased reasoning: adaptive responses to health risk feedback. Person Soc Psychol Bull. 2004;30(3):384-396.

25. Folkman S. Stress, coping, and hope. Psychooncology. 2010;19(9): 901-908.

26. Hagger MS, Orbell S. A meta-analytic review of the common-sense model of illness representations. Psychol Health. 2003;18(2):141-184.

27. Lazarus RS, Folkman S, editors. Stress, Appraisal, and Coping. New York: Springer; 1984.

28. Lobchuk MM, Bapuji SB, McClement SE, et al. What is the role of family in promoting faecal occult blood test screening? Exploring physician, average-risk individual, and family perceptions. Cancer Epidemiol. 2012;36(3):e190-e199.

29. Hall N, Birt L, Rees CJ, et al. Concerns, perceived need and competing priorities: a qualitative exploration of decision-making and nonparticipation in a population-based flexible sigmoidoscopy screening programme to prevent colorectal cancer. BMJ Open. 2016;6(11): e012304.

30. Lou S, Nielsen CP, Hvidman L, Petersen OB, Risør MB. Coping with worry while waiting for diagnostic results: a qualitative study of the experiences of pregnant couples following a high-risk prenatal screening result. BMC Pregnancy Childbirth. 2016;16(1):321.

31. Gaff CL, Clarke AJ, Atkinson P, et al. Process and outcome in communication of genetic information within families: a systematic review. Eur J Hum Genet. 2007;15(10):999-1011.

32. Beck U. Risk Society: Towards a New Modernity. London: SAGE; 1992.

33. Tulloch J, Lupton D. Risk and Everyday Life. London: SAGE Publications; 2003.

34. Lupton D. Medicine as Culture: Illness, Disease and the Body. 3rd ed. Thousand Oaks, CA: Sage; 2012.

35. Hall N, Birt L, Banks J, et al. Symptom appraisal and healthcare-seeking for symptoms suggestive of colorectal cancer: a qualitative study. BMJ Open. 2015;5(10):e008448.
Patient Preference and Adherence

\section{Publish your work in this journal}

Patient Preference and Adherence is an international, peer-reviewed, open access journal that focuses on the growing importance of patient preference and adherence throughout the therapeutic continuum. Patient satisfaction, acceptability, quality of life, compliance, persistence and their role in developing new therapeutic modalities and compounds to optimize

\section{Dovepress}

clinical outcomes for existing disease states are major areas of interest for the journal. This journal has been accepted for indexing on PubMed Central The manuscript management system is completely online and includes a very quick and fair peer-review system, which is all easy to use. Visit http://www. dovepress.com/testimonials.php to read real quotes from published authors. 